\title{
Thermodynamic analysis of porphyrin binding to Momordica charantia (bitter gourd) lectin
}

\author{
Nabil A. M. Sultan, Bhaskar G. Maiya* and Musti J. Swamy \\ School of Chemistry, University of Hyderabad, India
}

Owing to the use of porphyrins in photodynamic therapy for the treatment of malignant tumors, and the preferential interaction of lectins with tumor cells, studies on lectinporphyrin interaction are of significant interest. In this study, the interaction of several free-base and metalloporphyrins with Momordica charantia (bitter gourd) lectin (MCL) was investigated by absorption spectroscopy. Difference absorption spectra revealed that significant changes occur in the Soret band region of the porphyrins on binding to MCL. These changes were monitored to obtain association constants $\left(K_{\mathrm{a}}\right)$ and stoichiometry of binding. The tetrameric MCL binds four porphyrin molecules, and the stoichiometry was unaffected by the presence of the specific sugar, lactose. In addition, the agglutination activity of MCL was unaffected by the presence of the porphyrins used in this study, clearly indicating that porphyrin and carbohydrate ligands bind at different sites. Both cationic and anionic porphyrins bind to the lectin with comparable affinity $\left(K_{\mathrm{a}}=\right.$ $\left.10^{3}-10^{5} \mathrm{M}^{-1}\right)$. The thermodynamic parameters associated with the interaction of several porphyrins, obtained from the temperature dependence of the $K_{\mathrm{a}}$ values, were found to be in the range: $\Delta H^{\circ}=-98.1$ to $-54.4 \mathrm{~kJ} \cdot \mathrm{mol}^{-1}$ and $\Delta S^{\circ}=$ -243.9 to $-90.8 \mathrm{~J} \cdot \mathrm{mol}^{-1} \cdot \mathrm{K}^{-1}$. These results indicate that porphyrin binding to MCL is governed by enthalpic forces and that the contribution from binding entropy is negative. Enthalpy-entropy compensation was observed in the interaction of different porphyrins with MCL, underscoring the role of water structure in the overall binding process. Analysis of $\mathrm{CD}$ spectra of MCL indicates that this protein contains about $13 \% \alpha$-helix, $36 \% \beta$-sheet, $21 \% \beta$-turn, and the rest unordered structures. Binding of porphyrins does not significantly alter the secondary and tertiary structures of MCL.

Keywords: circular dichroism; enthalpy of binding; haemagglutinin; photodynamic therapy; secondary structure.
Lectins are a class of structurally diverse proteins grouped together because of their carbohydrate-binding property [1]. Although originally thought to be mediated primarily by hydrogen bonding between the hydroxy groups of the sugars and the polar side chains of the lectins, structural studies during the last two decades have clearly shown that, in addition to hydrogen bonding, the binding of carbohydrates to lectins is mediated by Van der Waals' forces, hydrophobic interactions, and metal co-ordination bonds [2-5]. Such diverse interactions are possible with carbohy-

Correspondence to M. J. Swamy, School of Chemistry, University of Hyderabad, Hyderabad 500 046, India. Fax: +91 402301 2460,

Tel.: +91 402301 1071, E-mail: mjssc@uohyd.ernet.in

Abbreviations: MCL, Momordica charantia lectin; SGSL, snake gourd

(Trichosanthes anguina) seed lectin; TCSL, Trichosanthes cucumerina seed lectin; PDT, photodynamic therapy; jacalin, jack fruit (Artocarpus integrifolia) agglutinin; ConA, concanavalin A; ZnTPPS, mesotetra-(4-sulfonatophenyl)porphyrinato zinc(II); $\mathrm{H}_{2}$ TPPS, meso-tetra(4-sulfonatophenyl)porphyrin; CuTCPP, meso-tetra-(4-carboxyphenyl)porphyrinato copper(II); $\mathrm{H}_{2} \mathrm{TCPP}$, meso-tetra-(4-carboxyphenyl)porphyrin; $\mathrm{H}_{2} \mathrm{TMPyP}$, meso-tetra-(4-methyl-pyridinium)porphyrin; CuTMPyP, meso-tetra-(4-methylpyridinium)porphyrinato copper(II); $\mathrm{NaCl} / \mathrm{P}_{\mathrm{i}}, 10 \mathrm{~mm}$ sodium phosphate buffer containing $0.15 \mathrm{M} \mathrm{NaCl}$ and $0.02 \%$ sodium azide, $\mathrm{pH} 7.4$.

* Note: deceased on 22 March 2004.

Note: a website is available at http://202.41.85.161/ mjs/

(Received 29 April 2004, revised 7 June 2004, accepted 21 June 2004) drates because of their unique structural features characterized by both polar and nonpolar surfaces.

Porphyrins are another class of biologically important molecules that possess both polar and nonpolar features in their expansive structures. Although they are primarily hydrophobic and exhibit low solubility in aqueous media, porphyrins can exhibit interesting polar interactions under certain conditions. Porphyrins are used as photosensitizers in photodynamic therapy (PDT), a new modality for the treatment of malignant tumors [6-9]. In PDT, porphyrin probably interacts with molecular oxygen on excitation by light of suitable wavelength and converts it into the singlet state. The singlet oxygen then reacts with the surrounding tissue, leading to cell necrosis [9]. Porphyrins have been used as photosensitizers in PDT because of their biocompatibility and their ability to preferentially localize in tumor cells. However, in most cases, the ratio of the photoactive porphyrin in the tumor tissue to that in the surrounding normal tissue is as low as $2: 1$ [10], which is clearly not adequate for the therapeutic application. A possible approach to overcome this limitation is to conjugate the porphyrin to another agent that can direct it to the tumor tissue. In view of the known ability of certain lectins to preferentially bind tumor cells [11], it appeared that lectins could be used as specific targeting agents for porphyrin photosensitizers in PDT. Previous studies reporting the preparation and evaluation of the efficacy of some lectindrug conjugates on tumor cells and animal models support the above idea [12-14]. Therefore, we initiated a long-term 
program to investigate the interaction of water-soluble porphyrins with lectins. In the initial studies, we characterized the interaction of several free-base and metalloporphyrins with plant lectins such as concanavalin A (ConA), pea lectin, jack fruit (Artocarpus integrifolia) agglutinin (jacalin), snake gourd (Trichosanthes anguina) seed lectin (SGSL) and Trichosanthes cucumerina seed lectin (TCSL) [15-18].

Momordica charantia lectin (MCL) is a tetrameric, galactose-specific glycoprotein with $\alpha_{2} \beta_{2}$-type subunit architecture [19]. Its macromolecular properties and carbohydrate-binding specificity towards monosaccharides and disaccharides have been investigated in considerable detail [19-23]. MCL exhibits strong type-1 and weak type-2 ribosome-inactivating protein activities as well as insulinomimetic activity [24-26]. In this study, we investigated the interaction of several water-soluble porphyrins with MCL. The thermodynamic forces governing the interaction of some of the porphyrins have been delineated from an analysis of the temperature dependence of the association constants. The results suggest that the interaction of porphyrins with MCL is governed by enthalpic forces, with the entropic contribution being negative.

\section{Materials and methods}

\section{Materials}

Seeds of bitter gourd were purchased locally. Guar gum, lactose and BSA were purchased from Sigma (St Louis, MO, USA). All porphyrins used were synthesized and characterized as described previously [27-31]. All other reagents were obtained from local suppliers and were of the highest purity available.

\section{Purification of MCL}

MCL was purified by a combination of ammonium sulfate precipitation and affinity chromatography on cross-linked guar gum [32], essentially as described previously [22]. The affinity-purified protein yielded a single band on PAGE [33], consistent with earlier reports $[19,22]$.

\section{Assay of MCL activity}

The activity of MCL was assessed by the agglutination and agglutination-inhibition assays using $\mathrm{O}(+)$ erythrocytes as described previously for TCSL [34]. To determine whether porphyrin binding altered the sugar-binding activity of the lectin, some of the agglutination experiments were conducted by preincubating the lectin with $25 \mathrm{~mm}$ mesotetra-(4-carboxyphenyl)porphyrinato copper(II) (CuTCPP), meso-tetra-(4-methylpyridinium)porphyrin $\left(\mathrm{H}_{2} \mathrm{TMPyP}\right)$, or meso-tetra-(4-sulfonatophenyl)porphyrin ( $\left.\mathrm{H}_{2} \mathrm{TPPS}\right)$.

\section{Absorption spectroscopy}

Absorption measurements were made on a Shimadzu Corporation (Kyoto, Japan) model UV-3101PC UV-VisNIR double-beam spectrophotometer using 1.0-cm path length cells. Temperature was maintained constant $\left( \pm 0.1^{\circ} \mathrm{C}\right)$ by means of a Peltier device supplied by the manufacturer.

\section{Determination of MCL concentration}

The concentration of MCL was determined by the method of Lowry et al. [35] using BSA as the standard, and by recording $A_{280}\left(1 \mathrm{mg} \cdot \mathrm{mL}^{-1}=1.062\right.$ absorbance units $)$ and expressed in subunits assuming an average subunit molecular mass of $30000 \mathrm{Da}$. Concentrations of porphyrins were determined spectrophotometrically using their molar absorptivities at the $\lambda_{\max }$ of the Soret band, as described [17].

\section{Porphyrin binding}

Porphyrin binding to MCL was investigated by the absorption titration method essentially as described previously for SGSL [17]. All titrations were performed in $10 \mathrm{~mm}$ sodium phosphate buffer containing $0.15 \mathrm{M} \mathrm{NaCl}$ and $0.02 \% \quad \mathrm{NaN}_{3}, \quad \mathrm{pH} 7.4 \quad\left(\mathrm{NaCl} / \mathrm{P}_{\mathrm{i}}\right)$. Porphyrin samples $(2.4 \mathrm{~mL}$ of $\approx 2.0-4.0 \mu \mathrm{M})$ were titrated by adding small aliquots of the lectin from a concentrated stock solution $\left(\approx 30 \mathrm{mg} \cdot \mathrm{mL}^{-1}\right)$ using a Hamilton (Reno, NV, USA) analytical micro syringe. An equal volume of the protein was added to the reference cell, to correct for any contribution to the absorption by the protein. UV-Vis spectra were recorded after an equilibration period of $2 \mathrm{~min}$ after each addition. The spectra were multiplied by an appropriate factor to correct for dilution effects in the intensities resulting from the addition of the protein. To ensure reproducibility, all titrations were performed at least twice, and mean values are reported for the association constants.

\section{CD spectroscopy}

$\mathrm{CD}$ spectra were recorded at $25^{\circ} \mathrm{C}$ on a Jasco J-810 spectropolarimeter (Jasco International Co., Ltd, Tokyo, Japan) available at the Central Instrumentation Laboratory, University of Hyderabad. Spectra were recorded at a scan speed of $20 \mathrm{~nm} \cdot \mathrm{min}^{-1}$ with a response time of $4 \mathrm{~s}$ and a slit width of $1.5 \mathrm{~nm}$. A cylindrical quartz cell of $1-\mathrm{mm}$ path length was used for measurements in the 200-250 nm range, and a cell of $10-\mathrm{mm}$ path length was used for measurements in the $250-300 \mathrm{~nm}$ range. All measurements were made at a fixed lectin subunit concentration of $24.8 \mu \mathrm{M}$ in the near-UV region, which was diluted 10 times for measurements in the far-UV region. Each spectrum reported is the mean of four successive scans. Measurements were made in $\mathrm{NaCl} / \mathrm{P}_{\mathrm{i}}$, and buffer scans recorded under the same conditions were subtracted from the protein spectra before further analysis. Spectra were also recorded in the presence of a 25-fold molar excess of CuTCPP or meso-tetra-(4-methylpyridinium)porphyrinato copper(II) (CuTMPyP) (resultant concentration of the porphyrin was $0.62 \mathrm{~mm}$ ), to investigate the effect of porphyrin binding on the protein conformation. For these spectra, a spectrum of the buffer containing the same concentration of porphyrin was subtracted from the experimental spectrum.

\section{Results}

A schematic diagram depicting the structure of various porphyrins used in this study is shown in Fig. 1 along with 

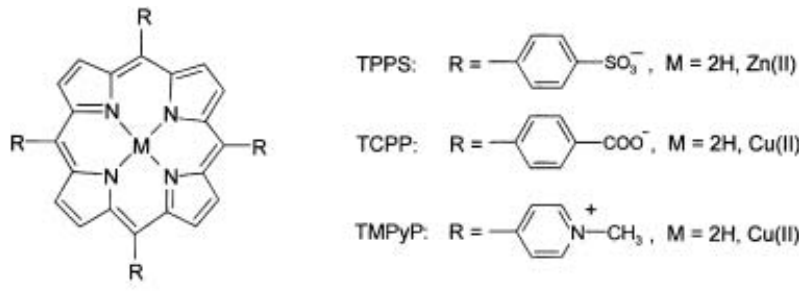

TCPP: $R=-C O 0^{\circ}, M=2 \mathrm{H}, \mathrm{Cu}$ (II)

TMPyP: $\mathrm{R}=\mathrm{N}^{+}-\mathrm{CH}_{3}, \mathrm{M}=2 \mathrm{H}, \mathrm{Cu}$ (II)

\begin{tabular}{lcc}
\hline Porphyrin & $\begin{array}{l}\lambda_{\max } \\
(\mathrm{nm})\end{array}$ & $\begin{array}{c}\varepsilon_{\max } \times 10^{-5} \\
\left(\mathrm{M}^{-1} \mathrm{~cm}^{-1}\right)\end{array}$ \\
\hline $\mathrm{H}_{2}$ TPPS & 413.0 & 3.65 \\
ZnTPPS & 422.0 & 3.70 \\
$\mathrm{H}_{2}$ TCPP & 414.0 & 2.00 \\
CuTCPP & 410.8 & 1.53 \\
ZnTCPP & 422.0 & 1.62 \\
$\mathrm{H}_{2}$ TMPyP & 422.0 & 1.90 \\
CuTMPyP & 424.8 & 2.75 \\
\hline
\end{tabular}

Fig. 1. Structures of the porphyrins investigated and wavelengths of maximum absorption $\left(\lambda_{\max }\right)$ and molar absorption coefficients $(\varepsilon)$ for their Soret absorption bands.

the corresponding $\lambda_{\max }$ and $\varepsilon_{\max }$ values for the Soret band. Some of these values were taken from our previous study [17]. All porphyrins used in the present study obeyed Beer's law up to $5 \mu \mathrm{M}$, indicating that under the conditions employed, the porphyrins were not aggregated [17].

\section{Porphyrin binding to MCL: absorption and difference absorption spectra}

Absorption spectra of CuTCPP (a tetra-anionic porphyrin) in the Soret band region in the absence and presence of different concentrations of MCL, recorded at $20{ }^{\circ} \mathrm{C}$, are shown in Fig. 2A. Spectrum 1 is that of CuTCPP alone, and spectra 2-14 correspond to CuTCPP in the presence of

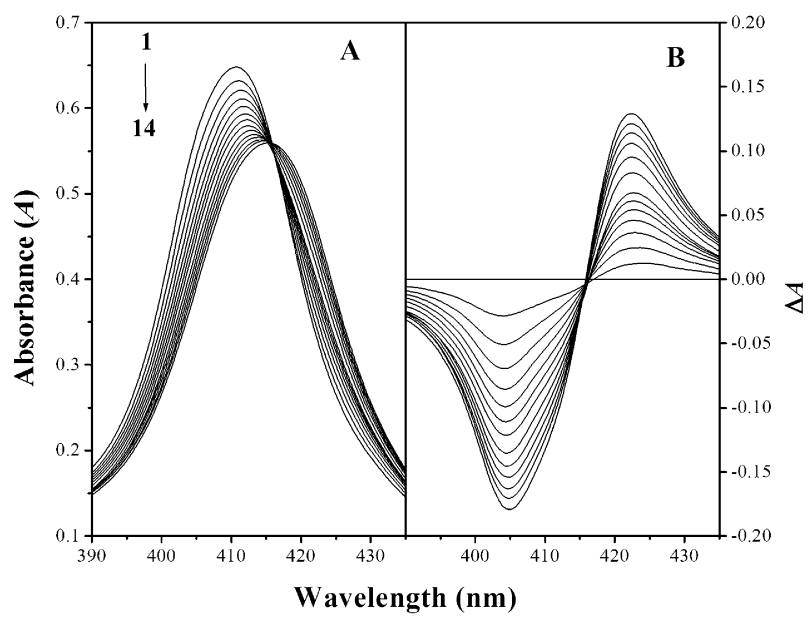

Fig. 2. (A) Absorption spectra of CuTCPP in the absence and presence of different concentrations of MCL and (B) difference absorption spectra obtained by subtracting the spectrum of CuTCPP alone from the spectra obtained in the presence of different concentrations of MCL. Temperature $=20^{\circ} \mathrm{C}$. increasing concentrations of MCL. From these spectra, it is clear that the absorption maximum of the Soret band of the porphyrin, seen at $410.8 \mathrm{~nm}$ (spectrum 1), shifts to longer wavelengths with a concomitant decrease in the absorption intensity in the presence of added lectin. At the highest concentration of lectin, the absorption maximum is seen at around $415.4 \mathrm{~nm}$ (spectrum 14). Difference spectra obtained by subtracting the spectrum of porphyrin alone from the spectra obtained in the presence of different concentrations of the lectin are shown in Fig. 2B. The difference spectra are characterized by a minimum around $405 \mathrm{~nm}$ and a maximum around $422.4 \mathrm{~nm}$. Titration of other anionic porphyrins, namely $\mathrm{H}_{2}$ TCPP, $\mathrm{H}_{2}$ TPPS and ZnTPPS, yielded absorption spectra and difference spectra with similar features (not shown).

Absorption spectra (Soret band region) of the tetracationic porphyrin, CuTMPyP, recorded in the absence (spectrum 1) and in the presence of increasing concentrations of MCL (spectra 2-14) are shown in Fig. 3A. The corresponding difference spectra are shown in Fig. 3B. The Soret band of CuTMPyP exhibits an absorption maximum around $424.8 \mathrm{~nm}$, the intensity of which decreases significantly on titration with MCL. However, the band position shifts only marginally, and, at the highest concentration of MCL (spectrum 14), it shifts to $426.2 \mathrm{~nm}$. The difference spectra in turn show a single minimum around $420.6 \mathrm{~nm}$ (Fig. 3B). Titration of another cationic porphyrin, $\mathrm{H}_{2} \mathrm{TMPyP}$, yielded qualitatively similar absorption spectra and difference spectra in the Soret band region (not shown).

\section{Analysis of association constants and thermodynamic parameters}

A binding curve depicting progress of the titration of CuTCPP with MCL is shown in Fig. 4. Increasing the lectin concentration leads to an increase in the change in absorption intensity; however, the magnitude of the change decreases with increasing lectin concentration and thus displays saturation behavior. The inset of this figure gives a

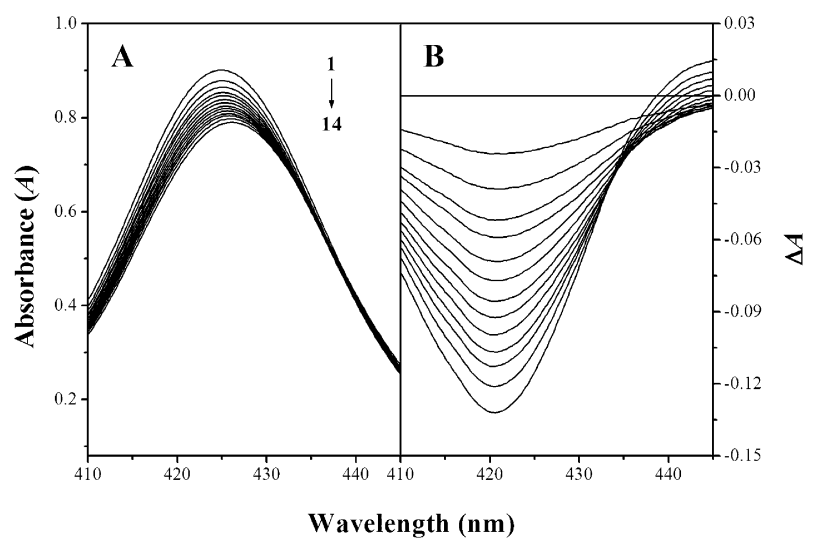

Fig. 3. (A) Absorption spectra of CuTMPyP in the absence and presence of different concentrations of MCL and (B) difference absorption spectra obtained by subtracting the spectrum of CuTMPyP alone from the spectra obtained in the presence of different concentrations of MCL. Temperature $=20^{\circ} \mathrm{C}$. 


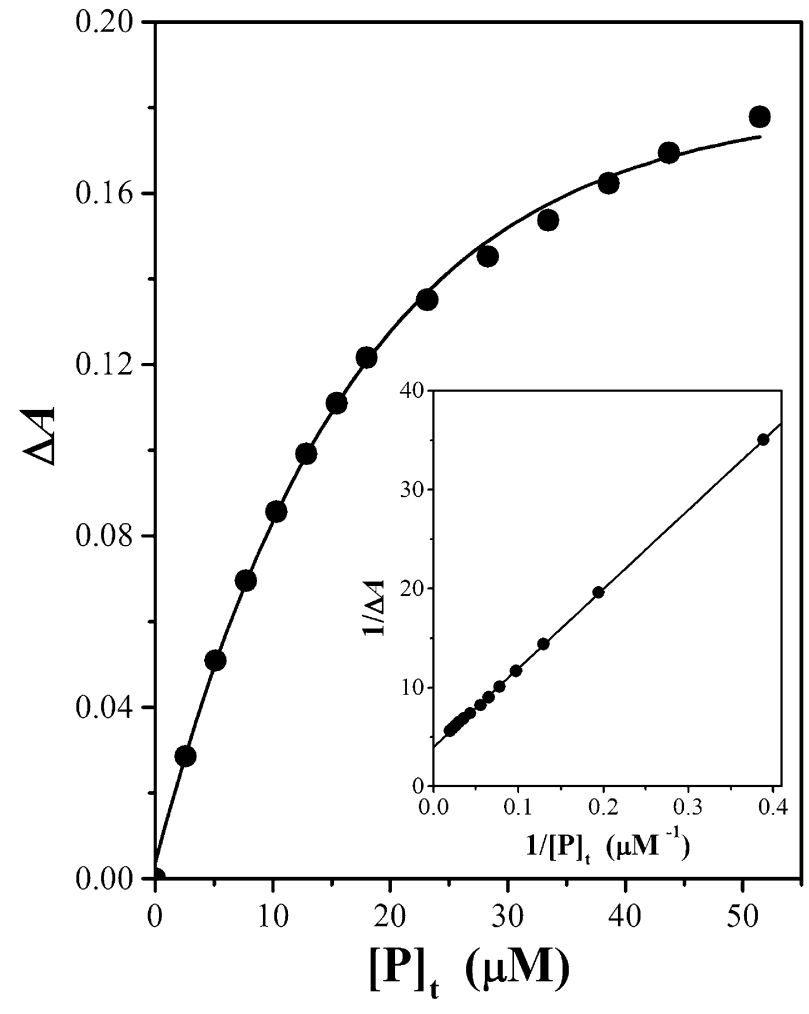

Fig. 4. Binding curve for the interaction of CuTCPP with MCL. The change in absorbance at $405 \mathrm{~nm}$ resulting from the addition of MCL to the porphyrin at $20{ }^{\circ} \mathrm{C}$ is plotted as function of the total lectin concentration (in subunits). Inset: plot of $1 / \Delta A$ as a function of the reciprocal total protein concentration. The reciprocal of the Y-intercept of this plot gave the value of $\Delta A_{\infty}$, the change in absorbance intensity when all the porphyrin molecules are bound by the lectin.

plot of $1 / \Delta A$ vs. $1 /[P]_{\mathrm{t}}$ where $\Delta A$ is the change in absorbance at any point of the titration, and $[P]_{\mathrm{t}}$ is the corresponding total concentration of MCL in subunits. The Y-intercept of this plot yields the change in absorbance at infinite protein concentration, $\Delta A_{\infty}$. From this, the absorption intensity of the porphyrin when it is completely bound to the lectin, $A_{\infty}$, can be determined. The titration data were analyzed according to the model of Sharon and colleagues [36], as described previously for the binding of porphyrins to other lectins [15-18]. From this analysis, the association constant, $K_{\mathrm{a}}$, characterizing the porphyrin-MCL interaction is determined according to eqn (1) [36]:

$$
\log \left[\Delta A /\left(A_{\mathrm{c}}-A_{\infty}\right)\right]=\log K_{\mathrm{a}}+\log [P]_{\mathrm{f}}
$$

where $[P]_{\mathrm{f}}$, the free protein concentration, is given by

$$
[P]_{\mathrm{f}}=[P]_{\mathrm{t}}-\left\{\left(\Delta A / \Delta A_{\infty}\right)[L]_{\mathrm{t}}\right\}
$$

From eqn (1) it is clear that the X-intercept of a plot of $\log \left[\Delta A /\left(A_{\mathrm{c}}-A_{\infty}\right)\right]$ vs. $\log [P]_{\mathrm{f}}$ will yield $\mathrm{p} K_{\mathrm{a}}$ for the lectinporphyrin association. A representative plot of $\log [\Delta A /$ $\left.\left(A_{\mathrm{c}}-A_{\infty}\right)\right]$ vs. $\log [P]_{\mathrm{f}}$ for the CuTCPP-MCL interaction at $20{ }^{\circ} \mathrm{C}$ is given in Fig. 5. This plot clearly shows that the data exhibit a linear dependence. The solid line represents a linear least squares fit of the data. The slope of this plot is found to

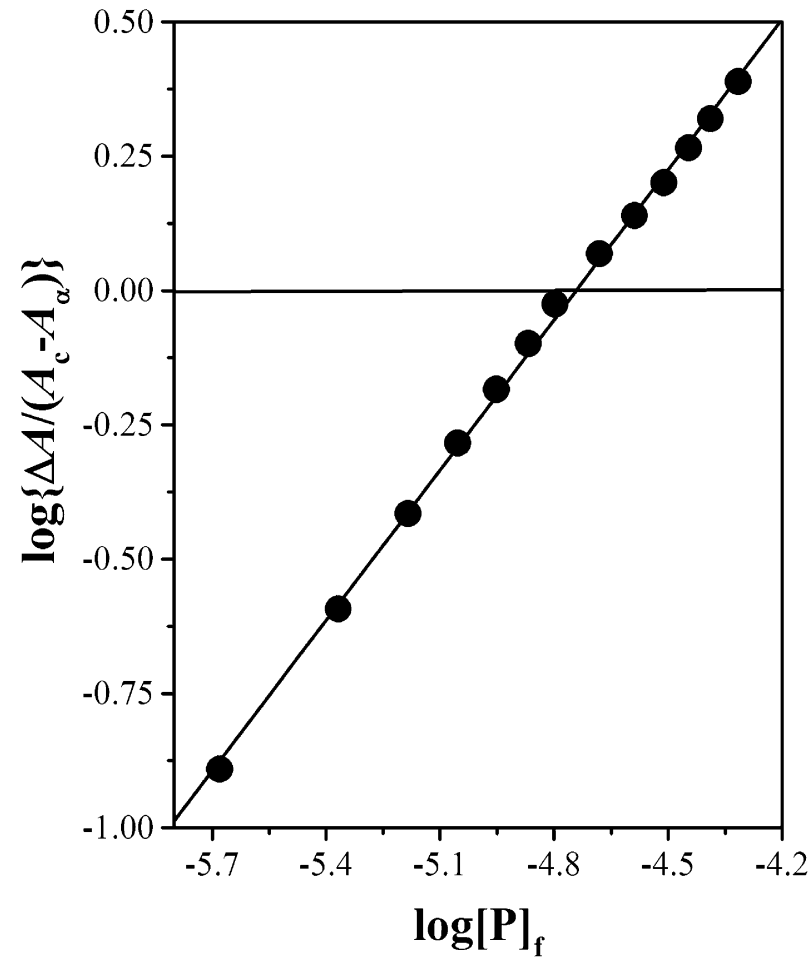

Fig. 5. Chipman plot for CuTCPP binding to MCL. The absorption titration data obtained at $20{ }^{\circ} \mathrm{C}$ for the CuTCPP-MCL interaction is analyzed as described by Chipman et al. [36]. The X-intercept yielded the value of $\mathrm{p} K_{\mathrm{a}}$ from which the association constant $K_{\mathrm{a}}$ was calculated.

be 0.94 , suggesting that each lectin subunit binds one porphyrin molecule. From the X-intercept of this plot, the $K_{\mathrm{a}}$ value for the CuTCPP-MCL interaction is determined as $5.85 \times 10^{4} \mathrm{M}^{-1}$. Following the same method, association constants for this interaction as well as those for the interactions of $\mathrm{H}_{2}$ TPPS, CuTMPyP and $\mathrm{H}_{2}$ TMPyP with MCL were determined at various temperatures. The $K_{\mathrm{a}}$ values obtained at $25{ }^{\circ} \mathrm{C}$ for all the porphyrins investigated in this study, together with the corresponding values of $\Delta A_{\infty}$ and the slopes of linear double logarithmic plots, are listed in Table 1. The $K_{\mathrm{a}}$ values obtained from similar analysis at different temperatures for CuTCPP, $\mathrm{H}_{2}$ TPPS, CuTMPyP and $\mathrm{H}_{2}$ TMPyP are listed in Table 2 .

From the association constants given in Table 1, the Gibbs free energies $\left(\Delta G^{\circ}\right)$ associated with the binding of different porphyrins to MCL were determined according to the expression:

$$
\Delta G^{\circ}=-\mathrm{R} T \ln K_{\mathrm{a}}
$$

These values are also listed in Table 1 .

The thermodynamic parameters, enthalpy of binding $\left(\Delta H^{\circ}\right)$ and entropy of binding $\left(\Delta S^{\circ}\right)$ associated with the interaction of CuTCPP, $\mathrm{H}_{2}$ TPPS, CuTMPyP and $\mathrm{H}_{2}$ TMPyP were obtained by means of van't Hoff plots (Fig. 6) according to the expression:

$$
\ln K_{\mathrm{a}}=\left(-\Delta H^{\circ} / \mathrm{R} T\right)+\left(\Delta S^{\circ} / \mathrm{R}\right)
$$

These values are also given in Table 2 . 
Table 1. Maximal change in the porphyrin absorption $\left(\Delta A_{\infty}\right)$ at infinite lectin concentration, the slopes from double logarithmic plots, the association constants $\left(K_{\mathrm{a}}\right)$, and the free energy of binding $\left(\Delta G^{\circ}\right)$ for MCL-porphyrin complexes at $25^{\circ} \mathrm{C}$. Mean values from duplicate titrations are given.

\begin{tabular}{lllll}
\hline Porphyrin & $\Delta A_{\infty}(\%)$ & Slope & $K_{\mathrm{a}} \times 10^{-4}\left(\mathrm{M}^{-1}\right)$ & $\Delta G^{\circ}\left(\mathrm{kJ} \cdot \mathrm{mol}^{-1}\right)$ \\
\hline CuTMPyP & 20.0 & 1.01 & 6.36 & -27.40 \\
$\mathrm{H}_{2}$ TMPyP & 20.0 & 0.99 & 4.49 & -26.55 \\
CuTCPP & 32.2 & 0.97 & 2.97 & -25.53 \\
$\mathrm{H}_{2}$ TCPP & 48.2 & 1.03 & 2.84 & -25.42 \\
ZnTPPS & 65.6 & 1.02 & 1.10 & -23.07 \\
$\mathrm{H}_{2}$ TPPS & 34.2 & 1.05 & 0.58 & -21.48 \\
\hline
\end{tabular}

Table 2. Association constants, $K_{\mathrm{a}}$, obtained at different temperatures for the interaction of CuTCPP, CuTMPyP, $\mathrm{H}_{2}$ TMPyP and $\mathrm{H}_{2}$ TPPS with MCL and the corresponding thermodynamic parameters, $\Delta H^{\circ}$ and $\Delta S^{\circ}$, obtained from the van't Hoff plots. Values shown in parentheses correspond to titrations performed in the presence of $0.1 \mathrm{M}$ lactose.

\begin{tabular}{lllll}
\hline \multirow{2}{*}{ Porphyrin } & $\begin{array}{l}T \\
\left({ }^{\circ} \mathrm{C}\right)\end{array}$ & $\begin{array}{l}K_{\mathrm{a}} \times 10^{-4} \\
\left(\mathrm{M}^{-1}\right)\end{array}$ & $\begin{array}{l}\Delta H^{\circ} \\
\left(\mathrm{kJ} \cdot \mathrm{mol}^{-1}\right)\end{array}$ & $\begin{array}{l}\Delta S^{\circ} \\
\left(\mathrm{J} \cdot \mathrm{mol}^{-1} \cdot \mathrm{K}^{-1}\right)\end{array}$ \\
\hline CuTMPyP & 20 & 9.08 & & \\
& 25 & 6.36 & -54.4 & -90.8 \\
& 25 & $(6.80)$ & & \\
& 30 & 4.35 & & -110.8 \\
$\mathrm{H}_{2}$ TMPyP & 20 & 6.60 & & \\
& 25 & 4.49 & -59.5 & \\
& 30 & 2.67 & & \\
& 35 & 2.10 & & -243.9 \\
CuTCPP & 35 & $(2.15)$ & & \\
& 10 & 25.32 & & -214.7 \\
& 15 & 10.26 & & \\
\hline $\mathrm{H}_{2}$ TPPS & 20 & 5.85 & & \\
& 25 & 2.97 & -98.1 & \\
& 25 & $(3.70)$ & & \\
& 25 & 0.98 & & \\
& 30 & 0.58 & -85.3 & \\
\hline
\end{tabular}

CD spectroscopy, secondary structure of MCL, and effect of porphyrin binding

CD spectra of MCL recorded in the far-UV region and near-UV region are given in Fig. 7A and 7B, respectively. Spectra obtained in the presence of a 25 -fold molar excess of CuTCPP and CuTMPyP are also shown. A fit of the CD spectrum of native MCL, obtained by analysing the spectrum using the CDSSTR program, is also given (details of the spectral analysis are given below). The spectrum of MCL in the far-UV region shows a minimum around $209 \mathrm{~nm}$ with a somewhat broad shoulder around 215$218 \mathrm{~nm}$. These spectral features suggested the presence of both $\alpha$-helix and $\beta$-sheet, but also indicated that the helix content is probably relatively low because the intensity around $222 \mathrm{~nm}$ (where $\alpha$-helix exhibits a significant negative intensity) was not significant. The near-UV spectrum has two prominent minima around $276 \mathrm{~nm}$ and $283 \mathrm{~nm}$ and a smaller minimum around $293 \mathrm{~nm}$. These features can be correlated with the contributions from the side chains of

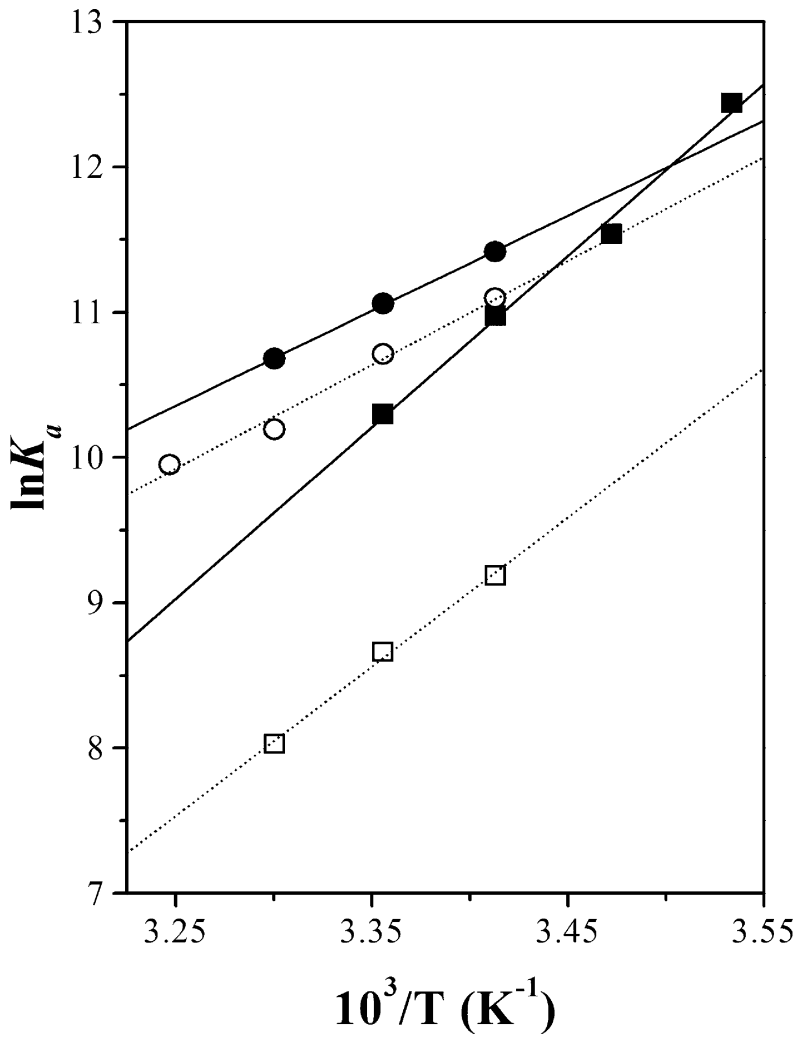

Fig. 6. Van't Hoff plots for the interaction of porphyrins with MCL. (I CuTCPP; ( $\square$ ) $\mathrm{H}_{2}$ TPPS; (๑) CuTMPyP; (○) $\mathrm{H}_{2}$ TMPyP.

tyrosine and tryptophan residues. The $\mathrm{CD}$ spectra obtained in the presence of porphyrins indicate that binding of either CuTCPP or CuTMPyP to MCL leads to very marginal changes in the secondary and tertiary structures of MCL.

To obtain more quantitative information on the secondary structure of MCL and the effect of ligand binding on it, the far-UV CD spectra of MCL in the native state as well as in the presence of CuTCPP and CuTMPyP were analysed by the CDSSTR program using the routines available in the website DICHROWEB (http://www.cryst.bbk.ac.uk/ cdweb/html/) [37-39]. Reference set 4 containing 43 proteins was used for fitting the experimental spectra. The results obtained from this analysis indicate that native MCL has $5 \%$ regular $\alpha$-helix and $8 \%$ distorted $\alpha$-helix which adds up to $13 \%$ of $\alpha$-helical structures. Regular $\beta$-sheet structure was $23 \%$ and distorted $\beta$-sheet was $13 \%$, yielding a total of $36 \%$ $\beta$-sheet. Of the remainder, $\beta$-turns account for $21 \%$ of the secondary structure of MCL, and unordered structures comprise about $31 \%$. The presence of either CuTCPP or CuTMPyP did not alter these values significantly.

\section{Discussion}

Considerable interest has been generated in recent years in the interaction of porphyrins with lectins with a view to using lectins as drug-delivery agents for porphyrin-based sensitizers in PDT. Previous studies from our laboratory have shown that a variety of water-soluble porphyrins bind with considerable avidity to different plant seed lectins, such as ConA, pea lectin, jacalin, SGSL and TCSL [15-18]. The 
Fig. 7. CD spectra of MCL alone and in the presence of porphyrins. The spectra were recorded at $25{ }^{\circ} \mathrm{C}$. (A) Far-UV region; (B) near-UV region. (-) Native MCL (experi-

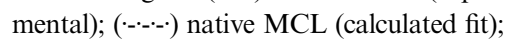
(…...) MCL + CuTMPyP; $(---)$ MCL + CuTCPP. The calculated fit matches the experimental spectrum of native MCL very well and hence is not clearly seen as the two lines overlap each other. The porphyrins were present at a 25-fold excess over MCL (subunit concentration). See text for details.

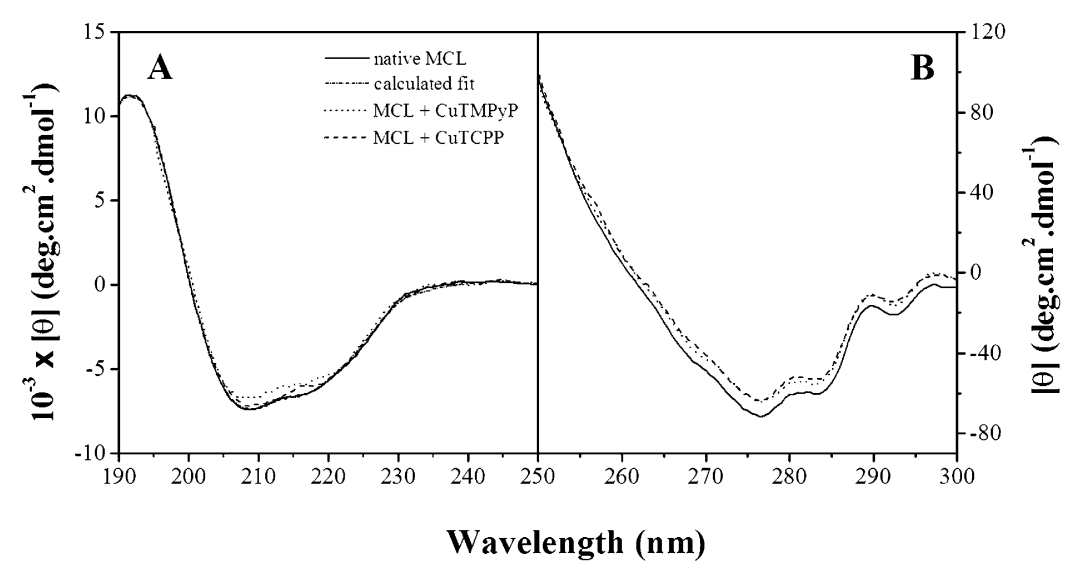

thermodynamic forces that stabilize the interaction of TCSL with a representative tetra-anionic porphyrin (CuTPPS) and a representative tetracationic porphyrin (CuTMPyP) have also been delineated by variable temperature studies [18]. It has been found that the binding of these two porphyrins to TCSL is largely driven by favorable entropic forces and that the enthalphic contribution is very small. In contrast, the results of the present study indicate that binding of porphyrins to MCL is enthalpically driven, with the entropic contribution being negative.

The binding data presented in Table 1 indicate that association constants for the interaction of different porphyrins with MCL at $25^{\circ} \mathrm{C}$ vary between $5 \times 10^{3} \mathrm{M}^{-1}$ and $1 \times 10^{5} \mathrm{M}^{-1}$. Association constants for the binding of CuTCPP, CuTMPyP and $\mathrm{H}_{2}$ TMPyP determined in the presence of $0.1 \mathrm{M}$ lactose are comparable to those obtained in the absence of any sugar (Table 2), clearly indicating that the porphyrin and sugar bind at different sites on the lectin surface. This is supported by hemagglutination experiments carried out in the presence of porphyrins, which indicated that the presence of CuTCPP, $\mathrm{H}_{2}$ TMPyP or $\mathrm{H}_{2}$ TPPS at a concentration of $25 \mathrm{mM}$ did not affect the cell agglutination activity of the lectin. Moreover, the addition of $0.1 \mathrm{~m}$ lactose to the CuTCPP-lectin complex did not reverse the changes induced by its binding to MCL in the absorption spectra of the porphyrin (not shown), further supporting the above interpretation. The range of $K_{\mathrm{a}}$ values obtained here for the interaction of different porphyrins with $\mathrm{MCL}$ is quite similar to that obtained for the interaction of the same porphyrins with the other Cucrbitaceae lectins, SGSL and TCSL $[17,18]$, but is somewhat higher than that reported for the interaction of different monosaccharides and disaccharides with MCL $[20,21,23]$. On the other hand, the binding of noncarbohydrate ligands that are primarily hydrophobic, such as adenine, 2,6-toludinylnaphthalenesulfonic acid, auxins and cytokinins, to a variety of plant lectins [40-44] and the binding of $\mathrm{H}_{2}$ TPPS to human serum albumin and $\beta$-lactoglobulin at neutral $\mathrm{pH}$ [45] are characterized by association constants in the range $1 \times 10^{5}-6 \times 10^{5} \mathrm{M}^{-1}$. Interestingly, the fact that auxins and cytokinins function as plant growth regulators [46] suggests that these molecules may act as endogenous ligands for plant lectins. The ability of tetracationic and tetra-anionic porphyrins to bind lectins strongly, as reported here and in our previous studies, indicates that, like auxins and cytokinins, porphyrins can also be considered potential endogenous ligands for plant lectins in their native tissues [16-18].

The thermodynamic parameters $\Delta H^{\circ}$ and $\Delta S^{\circ}$ obtained from the van't Hoff analysis of the $K_{\mathrm{a}}$ values for CuTCPP, $\mathrm{H}_{2}$ TPPS, CuTMPyP and $\mathrm{H}_{2}$ TMPyP (Table 2) indicate that binding of these porphyrins to MCL is governed by enthalpic forces and that the entropic contribution to the binding process is negative. The enthalpy and entropy of binding for the two tetracationic porphyrins, CuTMPyP and $\mathrm{H}_{2}$ TMPyP, are in the same range whereas the corresponding values for the tetra-anionic porphyrins, CuTCPP and $\mathrm{H}_{2}$ TPPS, are significantly different. This suggests that the specific interactions that mediate the binding of CuTMPyP and $\mathrm{H}_{2}$ TMPyP to the lectin are probably similar, whereas those that mediate the binding of CuTCPP and $\mathrm{H}_{2}$ TPPS to MCL could be different. Although the values of $\Delta H^{\circ}$ associated with the binding of CuTCPP $\left(-98.1 \mathrm{~kJ} \cdot \mathrm{mol}^{-1}\right)$ and $\mathrm{H}_{2}$ TPPS $(-85.3 \mathrm{~kJ}$. $\mathrm{mol}^{-1}$ ) are significantly larger than the corresponding values for CuTMPyP $\left(-54.4 \mathrm{~kJ} \cdot \mathrm{mol}^{-1}\right)$ and $\mathrm{H}_{2}$ TMPyP $(-59.5 \mathrm{~kJ}$. $\mathrm{mol}^{-1}$ ), this is compensated for by negative contributions from the entropy of binding, resulting in weaker association constants for CuTCPP and $\mathrm{H}_{2}$ TPPS than for the two TMPyP derivatives.

A comparison of the thermodynamic parameters $\Delta H^{\circ}$ and $\Delta S^{\circ}$ associated with the binding of different porphyrins to MCL (Table 2) with the corresponding values obtained for the binding of CuTPPS $\left(\Delta H^{\circ}=-15.06 \mathrm{~kJ} \cdot \mathrm{mol}^{-1}\right.$; $\left.\Delta S^{\circ}=43.93 \mathrm{~J} \cdot \mathrm{mol}^{-1} \cdot \mathrm{K}^{-1}\right)$ and CuTMPyP $\left(\Delta H^{\circ}=\right.$ $\left.-7.53 \mathrm{~kJ} \cdot \mathrm{mol}^{-1} ; \Delta S^{\circ}=67.78 \mathrm{~J} \cdot \mathrm{mol}^{-1} \cdot \mathrm{K}^{-1}\right)$ to TCSL [18] reveals that the thermodynamic forces that stabilize the binding in the two cases are very different. Whereas binding of porphyrins to TCSL is associated with positive $\Delta S^{\circ}$ values, which favor binding, interaction of porphyrins with MCL is predominantly driven by a stronger enthalpic contribution and the entropic contribution is negative (Table 2). This suggests that, whereas hydrophobic interactions such as van der Waals' interactions and stacking of aromatic side chains with the porphine core of the porphyrins, as observed in the jacalin- $\mathrm{H}_{2}$ TPPS interaction, most likely favor the binding of porphyrins to TCSL, porphyrin association with MCL must have a significant contribution from polar interactions such as hydrogen bonding, as observed in the ConA- $\mathrm{H}_{2}$ TPPS complex (see below). 


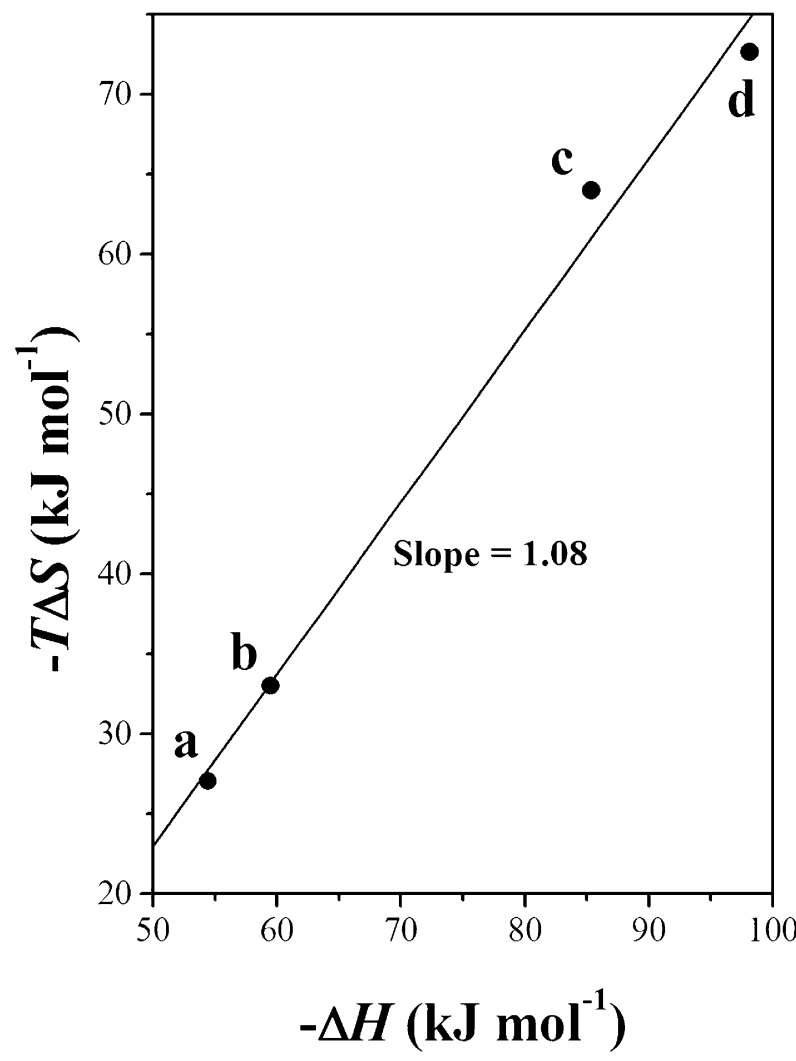

Fig. 8. Enthalpy-entropy compensation in porphyrin binding to MCL. The $\Delta H^{\circ}$ values for (a) CuTMPyP, (b) $\mathrm{H}_{2}$ TMPyP, (c) $\mathrm{H}_{2}$ TPPS and (d) CuTCPP were plotted as function of the $T \Delta S^{\circ}$ values $(\mathrm{T}=298 \mathrm{~K})$. The straight line represents a linear least squares fit of the data (slope $=1.08$ ).

A plot of $\Delta H^{\circ}$ vs. $\mathrm{T} \Delta S^{\circ}$ at $25^{\circ} \mathrm{C}$ for the binding of CuTCPP, $\mathrm{H}_{2}$ TPPS, CuTMPyP and $\mathrm{H}_{2}$ TMPyP to MCL is shown in Fig. 8. The data exhibit a linear dependence, clearly indicating that binding of porphyrins to MCL is characterized by enthalpy-entropy compensation. Enthalpyentropy compensation has been observed previously in the interaction of carbohydrates with several lectins [47-49]. This effect has been attributed to the crucial role played by water molecules, which are often involved in the making and breaking of critical hydrogen bonds in lectin-carbohydrate complexes [50]. It is also possible that conformational changes accompanying ligand binding lead to changes in the water structure. The thermodynamic studies presented here suggest that water molecules probably play a key role in the interaction of different porphyrins with MCL. Pertinently, single-crystal X-ray diffraction studies have shown that the binding of $\mathrm{H}_{2}$ TPPS to ConA is mediated exclusively by hydrogen bonds, some of which are water-mediated, whereas the porphine core of the porphyrin exhibits no interaction with the protein [51]. On the other hand, the 3D structure of the $\mathrm{H}_{2}$ TPPS-jacalin complex shows that binding of the same porphyrin to jacalin is mediated by a combination of hydrogen bonding and nonpolar interactions, including aromatic stacking interactions between the phenyl rings of the porphyrin and Tyr78 and Tyr122 of the lectin [52]. The thermodynamic data presented here, as discussed above, suggest that water-mediated hydrogen bonds may play a significant role in the binding of porphyrins to MCL.

Analysis of the CD spectra (Fig. 7) indicates that MCL is an $\alpha / \beta$ protein with larger $\beta$-sheet content $(\approx 36 \%)$ than $\alpha$-helical content $(13 \%)$. The observation that porphyrin binding does not result in significant changes in the secondary structure and tertiary structure of the protein clearly indicates that the lectin does not undergo any detectable conformational changes on binding of this ligand. X-ray diffraction studies indicate that binding of $\mathrm{H}_{2}$ TPPS to ConA does not lead to any detectable changes in the secondary and tertiary structures of the lectin [51], whereas considerable changes in the conformation of side chains, especially of aromatic residues such as Tyr, have been observed when the same porphyrin binds to jacalin [52]. The CD studies presented here suggest that porphyrin binding to MCL is probably similar to porphyrin binding by ConA, and most likely involves very marginal or no conformational changes of the protein.

\section{Conclusions}

The interaction of several free-base and metalloporphyrins with MCL has been investigated in this study. Thermodynamic parameters associated with the binding of several porphyrins indicate that the MCL-porphyrin interaction is stabilized by enthalpic forces and that the entropic contribution is negative. CD spectral studies indicate that MCL is an $\alpha / \beta$-type protein with a higher fraction of $\beta$-sheet than $\alpha$-helical content and that porphyrin binding does not significantly affect the secondary and tertiary structures of the protein. The significant affinity of CuTCPP, $\mathrm{H}_{2}$ TMPyP and CuTMPyP for MCL suggests that it may be possible to use MCL as a carrier for targeting these porphyrins to tumor tissues. Considering that bitter gourd (M. charantia) fruit forms part of the diet in the tropics, oral intake of porphyrin-MCL complexes is a possible route for administering the porphyrin photosensitizers in PDT. Further studies with cultured cells and animal models will be necessary to investigate further the possible application of MCL in PDT.

\section{Acknowledgements}

This work was supported by research projects from the Department of Science and Technology (India) to M.J.S. and B.G.M. N.A.M.S. is supported by a research fellowship from the Sanaá University of Yemen. We thank the UPE Program of the University Grants Commission (India) for some of the instrumentation facilities.

\section{References}

1. Lis, H. \& Sharon, N. (1998) Lectins: carbohydrate-specific proteins that mediate cellular recognition. Chem. Rev. 98, 637-674.

2. Drickamer, K. (1997) Making a fitting choice: common aspects of sugar-binding sites in plant lectins. Structure 5, 465-468.

3. Sharma, V. \& Surolia, A. (1997) Analyses of carbohydrate recognition by legume lectins: size of the combining site loops and their primary specificity. J. Mol. Biol. 267, 433-445.

4. Elgavish, S. \& Shaanan, B. (1998) Lectin-carbohydrate interactions: different folds, common recognition principles. Trends Biochem. Sci. 22, 462-467. 
5. Bouckaert, J., Hamelryck, T., Wyns, L. \& Loris, R. (1999) Novel structures of plant lectins and their complexes with carbohydrates. Curr. Opin. Struct. Biol. 9, 572-577.

6. Kessel, D. (1986) Sites of photosensitization by derivatives of hematoporphyrin. Photochem. Photobiol. 44, 489- 494.

7. Levy, G.J. (1995) Photodynamic therapy. Trends Biotechnol. 13, 14-18.

8. Dougherty, T.J., Gomer, C.J., Henderson, B.W., Jori, G., Kessel, D., Korbelik, M., Moan, J. \& Peng, Q. (1998) Photodynamic therapy. J. Natl Cancer Inst. 90, 889-905.

9. Bonnett, R. (1995) Photosensitizers of the porphyrin and phthalocyanine series for photodynamic therapy. Chem. Soc. Rev. 24, 1933.

10. Klyashchitsky, B.A., Nechaeva, I.S. \& Ponomaryov, G.V. (1994) Approaches to targetted photodynamic tumor therapy. Journal of Controlled Release 29, 1-16.

11. Lis, H. \& Sharon, N. (1986) Applications of lectins. In The Lectins. Properties, Functions and Applications in Biology and Medicine (Liener, I.E., Sharon, N. \& Goldstein, I.J., eds), pp. 293-370. Academic Press, New York.

12. Kitao, T. \& Hattori, K. (1977) Concanavalin A as a carrier of daunomycin. Nature (London) 265, 81-82.

13. Wirth, M., Fuchs, A., Wolf, M., Ertl, B. \& Gabor, F. (1998) Lectinmediated drug targeting: preparation, binding characteristics, and antiproliferative activity of wheat germ agglutinin conjugated doxorubicin on Caco-2 cells. Pharm. Res. 15, 1031-1037.

14. Lazzaro, G.E., Meyer, B.F., Willis, J.I., Erber, W.N., Herrmann, R.P. \& Davies, J.M. (1995) The synthesis of a peanut agglutininricin A chain conjugate: potential as an in vitro purging agent for autologous bone marrow in multiple myeloma. Exp. Hematol. 23, $1347-1352$.

15. Bhanu, K., Komath, S.S., Maiya, B.G. \& Swamy, M.J. (1997) Interaction of porphyrins with concanavalinA and pea lectin. Curr. Sci. 73, 598-603.

16. Komath, S.S., Bhanu, K., Maiya, B.G. \& Swamy, M.J. (2000) Binding of porphyrins by the tumor-specific lectin, Jacalin [jack fruit (Artocarpus integrifolia) agglutinin]. Biosci. Rep. 20, 265-276.

17. Komath, S.S., Kenoth, R., Giribabu, L., Maiya, B.G. \& Swamy, M.J. (2000) Fluorescence and absorption spectroscopic studies on the interaction of porphyrins with snake gourd (Trichosanthes anguina) seed lectin. J. Photochem. Photobiol. B Biol. $\mathbf{5 5}, 49-55$.

18. Kenoth, R., Reddy, D.R., Maiya, B.G. \& Swamy, M.J. (2001) Thermodynamic and kinetic analysis of porphyrin binding to Trichosanthes cucumerina seed lectin. Eur. J. Biochem. 268, 55415549.

19. Mazumder, T., Gaur, N. \& Surolia, A. (1981) The physicochemical properties of the galactose-specific lectin from Momordica charantia. Eur. J. Biochem. 113, 463-470.

20. Khan, M.I., Mazumder, T., Pain, D., Gaur, N. \& Surolia, A. (1981) Binding of 4-methylumbelliferyl- $\beta$-D-galactopyranoside to Momordica charantia agglutinin: fluorescence quenching studies. Eur. J. Biochem. 113, 471-476.

21. Das, M.K., Khan, M.I. \& Surolia, A. (1981) Fluorimetric studies of the binding of Momordica charantia (bitter gourd) lectin with ligands. Biochem. J. 195, 341-343.

22. Padma, P., Komath, S.S. \& Swamy, M.J. (1998) Fluorescence quenching and time-resolved fluorescence studies on Momordica charantia (bitter gourd) seed lectin. Biochem. Mol. Biol. Int. 45, 911-920.

23. Sultan, N.A.M. \& Swamy, M.J. (2003) Thermodynamic analysis of binding of 4-methylumbelliferyl- $\alpha$ - and $\beta$-D-galactopyranosides to Momordica charantia lectin. Curr. Sci. 84, 200-203.

24. Barbieri, L., Lorenzoni, E. \& Stirpe, F. (1979) Inhibition of protein synthesis in vitro by a lectin from Momordica charantia and by other haemagglutinins. Biochem. J. 182, 633-635.
25. Barbieri, L., Zamboni, M., Lorenzoni, E., Montanaro, L., Sperti, S. \& Stirpe, F. (1980) Inhibition of protein synthesis in vitro by proteins from the seeds of Momordica charantia (bitter pear melon). Biochem. J. 186, 443-452.

26. Ng, T.B., Wong, C.M., Li, W.W. \& Yeung, H.W. (1986) Isolation and characterization of a galactose binding lectin with insulinomimetic activities from the seeds of the bitter gourd Momordica charantia (family Cucurbitaceae). Int. J. Peptide Protein Res. 28, 163-172.

27. Fleishcher, E.B., Palmer, J.M., Srivastava, T.S. \& Chatterjee, A. (1971) Thermodynamic and kinetic properties of an iron-porphyrin system. J. Am. Chem. Soc. 93, 3162-3167.

28. Kadish, K.M., Maiya, G.B., Araullo, C. \& Guilard, R. (1989) Micellar effects on the aggregation of tetraanionic porphyrins. Spectroscopic characterization of free-base meso-tetrakis (4-sulfonatophenyl) porphyrin, (TPPS) $\mathrm{H}_{2}$ and (TPPS)M (M=Zn (II), $\mathrm{Cu}(\mathrm{II}), \mathrm{VO}^{+}$) in aqueous micellar media. Inorg. Chem. 28, 2725 2731.

29. Longo, F.R., Finarelli, M.G. \& Kim, J.B. (1969) The synthesis and some physical properties of $m s$-tetra (pentafluorophenyl)porphin and $m s$-tetra-(pentachlorophenyl)-porphin (1). J. Heterocycl. Chem. 6, 927-931.

30. Pasternack, R.F., Huber, P.R., Boyd, P., Engasser, G., Francesconi, L., Gibbs, E., Fasella, P., Venturo, G.C. \& Hinds, L.D. (1972) On the aggregation of meso-substituted water-soluble porphyrins. J. Am. Chem. Soc. 94, 4511-4517.

31. Pasternack, R.F., Francesconi, L., Ratt, D. \& Spiro, E. (1973) Aggregation of nickel (II), copper (II), and zinc (II) derivatives of water soluble porphyrins. Inorg. Chem. 12, 2606-2611.

32. Appukuttan, P.S., Surolia, A. \& Bachhawat, B.K. (1977) Isolation of two galactose-binding lectins from $R$. communis by affinity chromatography. Ind. J. Biochem. Biophys. 14, 382-384.

33. Laemmli, U.K. (1970) Cleavage of structural proteins during the assembly of the head of bacteriophage T4. Nature (London) 227, 680-685.

34. Padma, P., Komath, S.S., Nadimpalli, S.K. \& Swamy, M.J. (1999) Purification in high yield and characterisation of a new galactosespecific lectin from the seeds of Trichosanthes cucumerina. Phytochemistry 50, 363-371.

35. Lowry, O.H., Rosebrough, N.J., Farr, A.L. \& Randall, R.J. (1951) Protein measurement with the Folin phenol reagent. J. Biol. Chem. 193, 265-273.

36. Chipman, D.M., Grisaro, V. \& Sharon, N. (1967) The binding of oligosaccharides containing $N$-acetylglucosamine and $\mathrm{N}$-acetylmuramic acid to lysozyme. J. Biol. Chem. 242, 43884394.

37. Compton, L.A. \& Johnson, W.C. Jr (1986) Analysis of protein circular dichroism spectra for secondary structure using a simple matrix multiplication. Anal. Biochem. 155, 155-167.

38. Lobley, A. \& Wallace, B.A. (2001) DICHROWEB: a website for the analysis of protein secondary structure from circular dichroism spectra. Biophys. J. 80, 373a.

39. Lobley, A., Whitmore, L. \& Wallace, B.A. (2002) DICHROWEB: an interactive website for the analysis of protein secondary structure from circular dichroism spectra. Bioinformatics 18, 211-212.

40. Roberts, D.D. \& Goldstein, I.J. (1982) Hydrophobic binding properties of the lectin from lima beans (Phaseolus lunatus). J. Biol. Chem. 257, 11274-11277.

41. Roberts, D.D. \& Goldstein, I.J. (1983) Binding of hydrophobic ligands to plant lectins: titration with arylamino-naphtha lenesulfonates. Arch. Biochem. Biophys. 224, 479-484.

42. Maliarik, M.J. \& Goldstein, I.J. (1988) Photoaffinity labelling of the adenine binding sites of the lectins from lima bean, Phaseolus lunatus and the kidney bean, Phaseolus vulgaris. J. Biol. Chem. 263, 11274-11279. 
43. Gegg, C.V., Roberts, D.D., Segel, I.H. \& Etzler, M.E. (1992) Characterization of the adenine binding sites of two Dolichos biflorus lectins. Biochemistry 31, 6938-6942.

44. Puri, K.D. \& Surolia, A. (1994) Amino acid sequence of the winged bean (Psophocarpus tetragonolobus) basic lectin. J. Biol. Chem. 269, 30917-30926.

45. Andrade, S.M. \& Costa, S.M.B. (2002) Spectroscopic studies on the interaction of a water-soluble porphyrin and two drug carrier proteins. Biophys. J. 82, 1607-1619.

46. Roberts, J.A. \& Hooley, R. (1988) Plant Growth Regulators. Blackie, Glasgow.

47. Toone, E.J. (1994) Structure and energetics of protein-carbohydrate complexes. Curr. Opin. Struct. Biol. 4, 719-728.

48. Schwartz, F.P., Misquith, S. \& Surolia, A. (1996) Effect of substituents on the thermodynamics of D-galactopyranoside binding to concanavalin A, pea (Pisum sativum) lectin and lentil (Lens culinaris) lectin. Biochem. J. 316, 123-129.
49. Komath, S.S., Kenoth, R. \& Swamy, M.J. (2001) Thermdynamics of saccharide binding to snake gourd (Trichosanthes anguina) seed lectin. Fluorescence and absorption spectroscopic studies. Eur. J. Biochem. 268, 111-119.

50. Lemieux, R.U. (1996) How water provides the impetus for molecular recognition in aqueous solution. Acc. Chem. Res. 29, 373-380.

51. Goel, M., Jain, D., Kaur, K.J., Kenoth, R., Maiya, B.G., Swamy, M.J. \& Salunke, D.M. (2001) Functional equality in the absence of structural similarity. An added dimension to molecular mimicry. J. Biol. Chem. 276, 39277-39281.

52. Goel, M., Anuradha, P., Kaur, K.J., Maiya, B.G., Swamy, M.J. \& Salunke, D.M. (2004) Porphyrin binding to jacalin is facilitated by the inherent plasticity of the carbohydrate-binding site: novel mode of lectin-ligand interaction. Acta Crystallogr. D60, 281-288. 